\title{
Microfabricated Dual Sprayer for On-Line Mass Tagging of Phosphopeptides
}

\author{
Michel Prudent, ${ }^{\dagger}$ Joël S. Rossier, ${ }^{\ddagger}$ Niels Lion, ${ }^{\dagger, \S}$ and Hubert H. Giraultt, \\ Laboratoire d'Electrochimie Physique et Analytique, Ecole Polytechnique Fédérale de Lausanne, Station 6, CH-1015 \\ Lausanne, Switzerland, DiagnoSwiss SA, Route de l'lle au Bois 2, CH-1870 Monthey, Switzerland, and Service Regional \\ Vaudois de Transfusion Sanguine, Rue du Bugnon 27, CH-1005 Lausanne, Switzerland
}

Phosphopeptides tagging reactions by dinuclear zinc(II) complexes (1,3-bis[bis(2-pyridylmethyl)amino]-propan2-olato dizinc(II) ${ }^{3+}$, called tag) were performed with a dual-channel microsprayer in electrospray ionization mass spectrometry. The reaction is first studied ex situ and analyzed with a commercial electrospray source. In situ reactions (i.e., inside the Taylor cone) were achieved with a dual-channel microsprayer both with the tag synthesized chemically before the experiments and with the tag electrogenerated by in situ oxidation of a zinc electrode, also used to apply the electrospray current. The device consists of a polyimide microchip with two microchannels $(20 \mu \mathrm{m} \times 50 \mu \mathrm{m} \times 1 \mathrm{~cm})$ etched on each side of the structure and connecting only at the tip of the microchip. We demonstrate here that mixing two solutions with different physicochemical properties inside the Taylor cone can be used to selectively tag target molecules.

Post-translational modifications (PTMs) appear in the last step in the maturation of proteins, such as phosphorylation, glycosylation, or alkylation. Phosphorylation of proteins is the most studied PTM in living systems. It is a reversible modification adjusting folding and function of proteins, e.g., enzymatic activities or regulating protein localization, and it is involved in many crucial cell functions such as signal transduction, metabolic maintenance, or cell division. ${ }^{1}$ Four types of phosphorylation are known, ${ }^{2}$ all involving the addition of a phosphate group on an amino acid. O-phosphates are present on serine, tyrosine, and threonine residues and are the most common. N-, S-, and acyl-phosphorylations can mostly occur on histidine or lysine, cysteine, and aspartic or glutamic acid, respectively. Nowadays, all these PTMs are mostly well understood. However, the analysis of phosphoproteins and phosphopeptides remains a key challenge of proteome research. Indeed, the abundance of phosphoproteins is very low (1-2\% of native protein), and some special sample preparation and sample preconcentration are required to isolate phosphocompounds. $^{3}$

* To whom correspondence should be addressed. E-mail: hubert.girault@ epfl.ch. Fax: +41216933667.

$\dagger$ Ecole Polytechnique Fédérale de Lausanne.

* DiagnoSwiss SA.

\$ Service Régional Vaudois de Transfusion Sanguine.

(1) Hunter, T. Cell 2000, 100, 113-127.

(2) Sickmann, A.; Meyer, H. E. Proteomics 2001, 1, 200-206.

(3) Reinders, J.; Sickmann, A. Proteomics 2005, 5, 4052-4061.
The detection of phosphoproteins can be performed in 2D gels by phospho-specific stains or by western blotting techniques. These methods are quantitative and can detect all kinds of phosphorylation. Nevertheless, comigrating proteins can falsify the results; then a distinct stained protein plot is not necessarily representative of a unique protein and additional measurements such as mass spectrometry (MS) have to be performed. Moreover, the detection of phosphorylated proteins or peptides by MS is difficult due to their low ionization efficiencies. Indeed, in positive ionization mode, the ionization of these species depends of the number of basic residues, which contribute to the global net charge of the peptide or protein. Phosphorylation increases the acidity of peptides and hence decreases the protonation in a solution at $\mathrm{pH}$ values typically used in MS. Chemical modifications ${ }^{4-6}$ or phosphopeptide enrichment strategies have thus been developed. Liquid chromatography (LC) is a method of choice for sample preconcentration and coupling with MS. The isolation of phosphopeptides in affinity chromatography can be done either by retention on immobilized metal ion affinity chromatography ${ }^{7-10}$ or by immobilization in $\mathrm{TiO}_{2}$ columns. ${ }^{11,12}$ Electrostatic interactions between the stationary phase and the phosphopeptides allow the separation of the different compounds. To improve the detection by MS, several procedures have been developed such as the identification by metastable decomposition with a matrix-assisted laser desorption/ionization (MALDI) $\mathrm{MS}^{13}$ or by chemical modification, ${ }^{14-16}$ or such as the preconcentration with $\mathrm{Fe}^{3+}$.

(4) Tao, W. A.; Wollscheid, B.; O’Brien, R.; Eng, J. K.; Li, X. J.; Bodenmiller, B.; Watts, J. D.; Hood, L.; Aebersold, R. Nat. Methods 2005, 2, 591-598.

(5) Thompson, A. J.; Hart, S. R.; Franz, C.; Barnouin, K.; Ridley, A.; Cramer, R. Anal. Chem. 2003, 75, 3232-3243.

(6) Ficarro, S. B.; McCleland, M. L.; Stukenberg, P. T.; Burke, D. J.; Ross, M. M.; Shabanowitz, J.; Hunt, D. F.; White, F. M. Nat. Biotechnol. 2002, 20 , 301-305.

(7) Nuhse, T. S.; Stensballe, A.; Jensen, O. N.; Peck, S. C. Mol. Cell. Proteomics 2003, 2, 1234-1243.

(8) Porath, J.; Carlsson, J.; Olsson, I.; Belfrage, G. Nature 1975, 258, 598599.

(9) Bodenmiller, B.; Mueller, L. N.; Mueller, M.; Domon, B.; Aebersold, R. Nat. Methods 2007, 4, 231-237.

(10) Stensballe, A.; Andersen, S.; Jensen, O. N. Proteomics 2001, 1, 207-222.

(11) Sano, A.; Nakamura, H. Anal. Sci. 2004, 20, 861-864.

(12) Pinkse, M. W. H.; Uitto, P. M.; Hilhorst, M. J.; Ooms, B.; Heck, A. J. R. Anal. Chem. 2004, 76, 3935-3943.

(13) Annan, R. S.; Carr, S. A. Anal. Chem. 1996, 68, 3413-3421.

(14) Adamczyk, M.; Gebler, J. C.; Wu, J. Rapid Commun. Mass Spectrom. 2002, 16, 999-1001.

(15) Kuyama, H.; Toda, C.; Watanabe, M.; Tanaka, K.; Nishimura, O. Rapid Commun. Mass Spectrom. 2003, 17, 1493-1496. 
loaded agarose beads incorporated in a matrix. ${ }^{17}$ Takeda et al. ${ }^{18}$ have introduced a method based on a mass shift induced by a metallic complex. 1,3-Bis[bis(2-pyridylmethyl)amino]propan-2olato dizinc(II) ${ }^{3+}$ (called thereafter tag) complex is able to trap phosphorylated compounds and after elution allows their detection by MALDI-MS. It has also been used in sodium dodecyl sulfate polyacrylamide gel electrophoresis to increase the detection and affect the migration of phosphorylated and nonphosphorylated proteins. ${ }^{19}$ This tag binds to phosphate via two atoms of zinc partially coordinated. ${ }^{20}$

MS has been used for a long time to study inorganic complexes especially since the introduction of soft ionization techniques such as electrospray ionization (ESI). ${ }^{21}$ In this technique, numerous microfabricated electrospray devices have been developed and have shown a better sensitivity than commercial electrospray sources, by reducing the flow rate for instance. ${ }^{22,23}$ This benefit is less important at typical flow rates above a few hundred nanoliters per minute, and the main advantage (compare to classical ESI source) remains the limited sample consumption. Smith and co-workers have proposed various emitters and a multicapillary inlet to improve MS sensitivity. ${ }^{24-26}$ Henion's group and Advion Biosciences developed silicon microchips for quantification of drugs and proteomics. ${ }^{27-29}$ Our laboratory has developed such polymer microsprayers based on various material, geometries, and configurations. ${ }^{30-32}$ Here, dual-channel microchips have been fabricated via polyimide plasma etching. ${ }^{33,34}$ These microsprayers are made of two different channels connected only at the tip of the emitter. In this way, two liquids are mixed within

(16) Blacken, G. R.; Gelb, M. H.; Turecek, F. Anal. Chem. 2006, 78, 60656073.

(17) Zhou, W.; Merrick, B. A.; Khaledi, M. G.; Tomer, K. B. J. Am. Soc. Mass Spectrom. 2000, 11, 273-282.

(18) Takeda, H.; Kawasaki, A.; Takahashi, M.; Yamada, A.; Koike, T. Rapid Commun. Mass Spectrom. 2003, 17, 2075-2081.

(19) Kinoshita, E.; Kinoshita-Kikuta, E.; Takiyama, K.; Koike, T. Mol. Cell. Proteomics 2006, 5, 749-757.

(20) Kinoshita, E.; Takahashi, M.; Takeda, H.; Shiro, M.; Koike, T. Dalton Trans. 2004, 1189-1193.

(21) Henderson, W.; McIndoe, J. S. Mass Spectrometry of Inorganic, Coordination and Organometallic Compounds: Tools-Techniques-Tips, 1st ed.; John Wiley \& Sons: Chichester, 2005.

(22) Lion, N.; Rohner, T. C.; Dayon, L.; Arnaud, I. L.; Damoc, E.; Youhnovski, N.; Wu, Z. Y.; Roussel, C.; Josserand, J.; Jensen, H.; Rossier, J. S.; Przybylski, M.; Girault, H. H. Electrophoresis 2003, 24, 3533-3562.

(23) Koster, S.; Verpoorte, E. Lab Chip 2007, 7, 1394-1412.

(24) Tang, K.; Lin, Y.; Matson, D. W.; Kim, T.; Smith, R. D. Anal. Chem. 2001, 73, 1658-1663.

(25) Kelly, R. T.; Page, J. S.; Tang, K.; Smith, R. D. Anal. Chem. 2007, 79, 41924198.

(26) Kim, T.; Tang, K.; Udseth, H. R.; Smith, R. D. Anal. Chem. 2001, 73, 41624170.

(27) Dethy, J. M.; Ackermann, B. L.; Delatour, C.; Henion, J. D.; Schultz, G. A Anal. Chem. 2003, 75, 805-811.

(28) Schultz, G. A.; Corso, T. N.; Prosser, S. J.; Zhang, S. Anal. Chem. 2000, 72, 4058-4063.

(29) Zhang, S.; Van Pelt, C. K.; Henion, J. D. Electrophoresis 2003, 24, 36203632.

(30) Rohner, T. C.; Rossier, J. S.; Girault, H. H. Anal. Chem. 2001, 73, 53535357.

(31) Gobry, V.; Van Oostrum, J.; Martinelli, M.; Rohner, T. C.; Reymond, F.; Rossier, J. S.; Girault, H. H. Proteomics 2002, 2, 405-412.

(32) Dayon, L.; Abonnenc, M.; Prudent, M.; Lion, N.; Girault, H. H. J. Mass Spectrom. 2006, 41, 1484-1490.

(33) Rossier, J. S.; Vollet, C.; Carnal, A.; Lagger, G.; Gobry, V.; Girault, H. H.; Michel, P.; Reymond, F. Lab Chip 2002, 2, 145-150.

(34) Lion, N. Ph.D. Thesis 3462, Ecole Polytechnique Fédérale de Lausanne, Lausanne, 2006.
Chart 1. 1,3-Bis[bis(2-pyridylmethyl)amino]propan-2-olato Dizinc (II) ${ }^{3+}$ Bound to a Phosphate Group

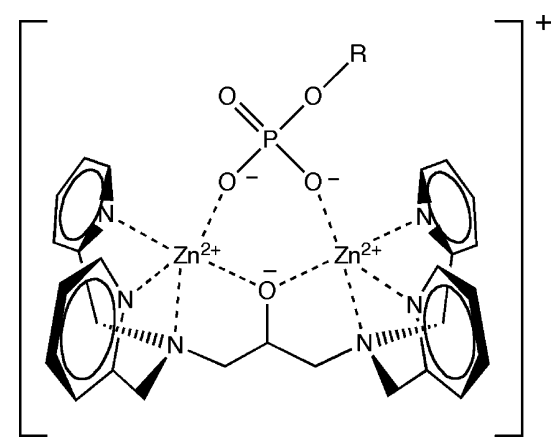

the Taylor cone $\mathrm{e}^{35}$ formed at the junction of the two microchannels during the ESI process. ${ }^{36,37}$ Chen et al. have used a similar approach but with two tapered capillaries used to bring a sheath liquid after capillary electrophoresis. ${ }^{38}$

ESI is also known to imply a number of electrochemical processes. ${ }^{39}$ An electrospray device acts as an anode when operating in positive ionization mode, so that $\mathrm{Zn}^{2+}$ cations can be produced on-line electrochemically when a zinc anode is used. Blades et al. have characterized this electrogeneration by using a $\mathrm{Zn}$ capillary tip. ${ }^{40} \mathrm{~A}$ sacrificial electrode can be used to support the electrospray current and the production of metallic cations. ${ }^{41,42}$ In our laboratory, these kinds of sacrificial electrodes have been coupled to microsprayers for the on-line study of different reactions. ${ }^{43,44}$ The anode made of zinc is easily oxidized at low redox potentials $\left(E^{0}{ }_{\mathrm{Zn} 2+/ \mathrm{Zn}}=-0.76 \mathrm{~V}\right.$ vs SHE). Here, electrogenerated $\mathrm{Zn}^{2+}$ cations form a stable dinuclear zinc(II) complex with 1,3-bis[bis(2-pyridylmethyl)amino]-2-propanol (LH) able to react specifically with phosphorylated compounds (Chart 1 ).

In the present work, we use the intrinsic design of dual-channel microsprayers to follow the specific binding of a tag with phosphopeptides in ESI-MS. First, the reaction is achieved ex situ (in a microtube) by using a synthesized zinc(II) complex and analyzed with a commercial electrospray source. Second, this reaction is performed in situ, i.e., within the Taylor cone, again with the synthesized zinc(II) complexes. Finally, the tag synthesis is performed on-line by electrogeneration of $\mathrm{Zn}_{2} \mathrm{~L}^{3+}$ prior to the chemical tagging reaction within the Taylor cone.

(35) Taylor, G. Proc. R. Soc. London, Series A: Math. Phys. Sci. 1964, 280, 383397.

(36) Cole, R. B. Electrospray Ionization Mass Spectrometry: Fondamentals Instrumentation \& Applications, 1st ed.; John Wiley \& Sons: New York, 1997.

(37) Rohner, T. C.; Lion, N.; Girault, H. H. Phys. Chem. Chem. Phys. 2004, 6 , 3056-3068.

(38) Chen, Y. R.; Tseng, M. C.; Her, G. R. Electrophoresis 2005, 26, 1376-1382.

(39) Van Berkel, G. J.; Kertesz, V. Anal. Chem. 2007, 79, 5510-5520.

(40) Blades, A. T.; Ikonomou, M. G.; Kebarle, P. Anal. Chem. 1991, 63, 21092114.

(41) Van Berkel, G. J.; Asano, K. G.; Schnier, P. D. J. Am. Soc. Mass Spectrom. 2001, 12, 853-862.

(42) Van Berkel, G. J.; Kertesz, V. J. Mass Spectrom. 2001, 36, 1125-1132.

(43) Prudent, M.; Roussel, C.; Girault, H. H. Electrochem. Commun. 2007, 9, 2067-2074.

(44) Rohner, T. C.; Girault, H. H. Rapid Commun. Mass Spectrom. 2005, 19, $1183-1190$. 

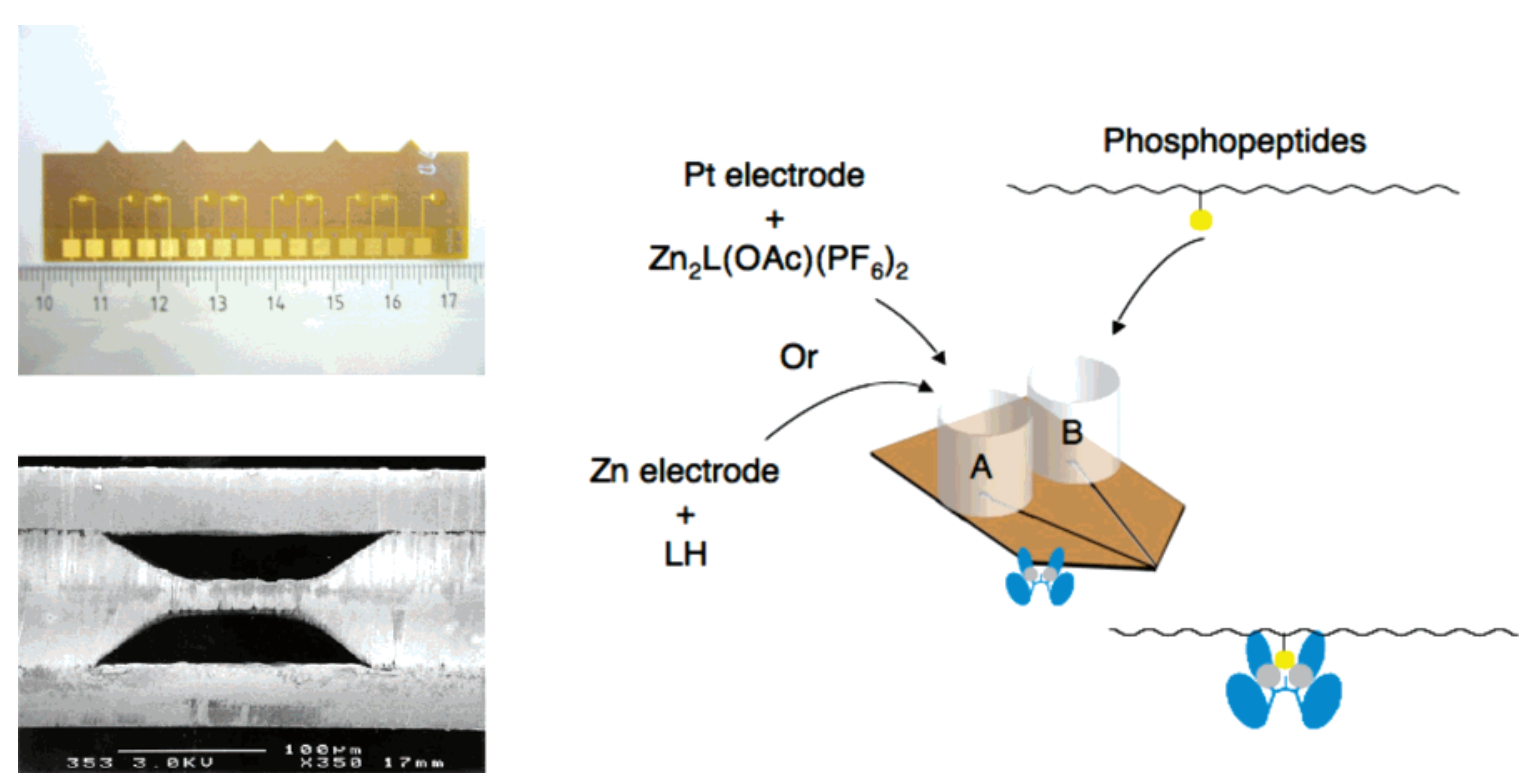

Figure 1. Top: picture of a bar of 5 dual-channel microsprayers. Bottom: scanning electron microscopy picture of a cross section of a microchip tip, illustrating the superposition of the channels, one above and one below the plane (bigger microchannels are used as example). Right: schematic representation of the experiments performed with a dual-channel microchip. Well $A$, tag solution and Pt electrode or ligand solution and $\mathrm{Zn}$ electrode; well B, phosphopeptides sample.

\section{EXPERIMENTAL SECTION}

Chemicals. The ligand 1,3-bis[bis(2-pyridylmethyl)amino]-2propanol (LH, $M=454.57 \mathrm{~g} / \mathrm{mol}, 10 \%$ in 2-propanol), 2-propanol, potassium hexafluorophosphate, and triethylamine were bought from Fluka (Buchs, Switzerland). Zinc acetate dihydrate (Zn$(\mathrm{OAc})_{2} \cdot 2 \mathrm{H}_{2} \mathrm{O}$ ) was from Aldrich (Milwaukee, WI) and methanol from Riedel-de-Haën (Seelze, Germany). Two nonphosphorylated peptides, human angiotensin II (angII, DRVYIHPF, $M=1046.2$ $\mathrm{g} / \mathrm{mol}$ ) and bradykinin (brady, RPPGFSPFR, $M=1060.2 \mathrm{~g} / \mathrm{mol}$ ) were from Bachem (Bubendorf, Switzerland) and from Sigma (St. Louis, MO), respectively. Two phosphopeptides, p_angiotensin II (p_angII, DRVpYIHPF, $M=1126.16 \mathrm{~g} / \mathrm{mol}$ ) and keratin K18 (RPVSSAApSVYAGAC, $M=1418.47 \mathrm{~g} / \mathrm{mol}$ ), were purchased from AnaSpec (San Jose, CA). They were used as received. Deionized water $(18.2 \mathrm{M} \Omega \cdot \mathrm{cm})$ was prepared using a Milli-Q system from Millipore (Bedford, MA) and acetonitrile (ACN) was from sds (Val de Reuil, France).

Synthesis of the Dinuclear Zinc(II) Complex $\left(\mathrm{Zn}_{2} \mathrm{~L}(\mathrm{OAc})\right.$ $\left.\left(\mathrm{PF}_{6}\right)_{2}\right)$. The acetate-bound 1,3-bis[bis(2-pyridylmethyl)amino]propan-2-olato dizinc(II) complex $\left(\mathrm{Zn}_{2} \mathrm{~L}(\mathrm{OAc})\left(\mathrm{PF}_{6}\right)_{2}\right)$ was synthesized according to Adams et al. ${ }^{45}$ It was prepared by adding 2 equiv of $\mathrm{Zn}(\mathrm{OAc})_{2} \cdot 2 \mathrm{H}_{2} \mathrm{O}(26 \mathrm{mg})$ to a warn methanolic $(10 \mathrm{~mL})$ solution of $\mathrm{LH}$ (1 equiv, $334 \mu \mathrm{L}$ ) and triethylamine (1 equiv, 8.4 $\mu \mathrm{L})$. The counterion $\left(\mathrm{KPF}_{6}, 2\right.$ equiv, $\left.22.1 \mathrm{mg}\right)$ was added when the dissolution was complete. The solution was heated at reflux for $30 \mathrm{~min}$ and then cooled at room temperature. White crystals (soluble in ACN) were thus formed (yield 33\%) with an $m / z=$ $320.1 \mathrm{Th}$ for ${ }^{64} \mathrm{Zn}_{2} \mathrm{~L}(\mathrm{OAc})^{2+}$. This zinc(II) complex was used without further purification. The term tag refers to the part reacting with the phosphate moiety, i.e., $\mathrm{Zn}_{2} \mathrm{~L}^{3+}$.

MS Setup and Microspray Interface. A LCQ DUO ion trap mass spectrometer (Thermo, San Jose, CA) was used in positive ionization mode. The heated capillary was kept at $200{ }^{\circ} \mathrm{C}$. The

(45) Adams, H.; Bradshaw, D.; Fenton, D. E. J. Chem. Soc., Dalton Trans. 2002, 925-930. commercial electrospray interface was removed and the microchip was mounted on a plate fixed on the probe slide adapter of the mass spectrometer. After the MS power supply onset $(U=3.5$ $\mathrm{kV}$ ), the chip was moved closer to the entrance of the MS. The current was set between 30 and $80 \mathrm{nA}$ by adjusting the distance between the microspray outlet and the entrance of the MS, and was monitored by a nanoammeter. Optimization of mass spectrometer optics parameters was usually realized on p_angII. The mass spectra were averaged on $1 \mathrm{~min}$.

The microspray interface consists of a double microchannel $(20 \mu \mathrm{m} \times 50 \mu \mathrm{m} \times 1 \mathrm{~cm})$ polyimide microchip developed by DiagnoSwiss SA (Monthey, Switzerland) ${ }^{31,33}$ The microchannels were plasma etched on both side of the microchip and thermally laminated (see Figure 1) ${ }^{34}$ Polycarbonate reservoirs (i.d. $=6.5$ $\mathrm{mm}, h=5 \mathrm{~mm}$ ) were glued at the inlet of each microchannel, both reservoirs being above the plane. Solutions were loaded ( $V$ $=100 \mu \mathrm{L})$ in these wells, and a microspray electrode was immersed in one reservoir only. This electrode made of platinum or zinc was sanded and rinsed with methanol before each experiment. Figure 1 (right) summarizes the experiments carried out with the dual-channel microsprayer. First, well A was filled with the dinuclear zinc(II) complex solution (5, 10, 20, 50, or 100 $\mu \mathrm{M}$ in $\mathrm{ACN})$ and well B with the peptide mixture (50 $\mu \mathrm{M}$ of each peptide in $\mathrm{H}_{2} \mathrm{O}$ ). The voltage was applied with a platinum electrode placed in well A. Second, wells A and B were filled with the ligand solution $(5,10,20$, or $50 \mu \mathrm{M}$ in 2-propanol; $\mathrm{LH}$ is stocked in 2-propanol) and the peptide mixture (50 $\mu \mathrm{M}$ of each peptide in $\mathrm{H}_{2} \mathrm{O}$ ), respectively. A zinc electrode was immersed in well A for the electrogeneration of $\mathrm{Zn}_{2} \mathrm{~L}^{3+}$. These two experiments were performed in 2-propanol and acetonitrile. 2-Propanol is more viscous and induces a lower flow rate (see equations in next section) potentially resulting in better ionization efficiency. However, because the flow rate is inversely proportional to the fluid viscosity (see below), at low flow rates, the influence of fluid viscosity is limited. Further experiments were run with a com- 
mercial electrospray source at different concentrations of tag in $50 / 50 \mathrm{ACN} / \mathrm{H}_{2} \mathrm{O}(\mathrm{v} / \mathrm{v})$.

Conversion Rates Calculation. Conversion rates $\chi$ were calculated as follows:

$$
\chi=\frac{I\left(\mathrm{p} \_ \text {ang } I^{*}{ }^{+}\right)+I\left(\mathrm{p} \_ \text {ang } I I^{*^{2+}}\right)}{I\left(\text { p_angII }^{*}\right)+I\left(\mathrm{p} \_ \text {ang } I I^{*^{2+}}\right)+I\left(\mathrm{p} \_ \text {ang } I^{+}\right)}
$$

or

$$
\chi=\frac{I\left(\mathrm{~K} 18^{\star^{2+}}\right)}{I\left(\mathrm{~K} 18^{\star 2+}\right)+I\left(\mathrm{~K} 18^{+}\right)}
$$

where $I$ is the relative abundance observed in MS and * represents the tagged phosphopeptide. In the case of p_angII*, the monocharged complex was also considered due to its relative abundance. For K18*, only the doubly charged ion was observed. The relative abundance is not directly correlated to the analyte concentration. The signal increases linearly with the concentration (up to $10^{-5} \mathrm{M}$ ) and then reaches a plateau. Moreover, since different analytes ionize differently in electrospray, their relative intensities may not directly relate to their concentration ratio and a lower concentration of p_angII* compared to p_angII could produce higher peak intensity. ${ }^{36,46}$ Thus, the calculated $\chi$ values stand for the observed conversion rate in mass spectrometry and are related to the concentration of the compounds in solution but do not provide the real conversion rate. Indeed, ionization efficiency between the tagged and untagged peptide can be different. This parameter will be used in a qualitative manner. In addition, the errors on $\chi$ are more important at the extrema due to the signal noise $\left(\sim 10^{3}\right.$ counts).

\section{RESULTS AND DISCUSSION}

Tagging Analysis with a Commercial Electrospray Source. A mixture of peptides (phosphorylated and nonphosphorylated) was used as a model system. The reaction was performed in a microtube at different tag concentrations (in 50/50 ACN/ $\mathrm{H}_{2} \mathrm{O}(\mathrm{v} /$ v)) prior to the MS analysis, and no incubation time was required because the tagging reaction is relatively fast. No evolution of $\chi$ was observed with time (the first measure was taken after roughly $1 \mathrm{~min})$, and to our knowledge, there is no available kinetic data in the literature about the complexation rate. The solution was sprayed with a commercial electrospray source. The tag can react with the phosphate group as shown in MALDI-MS by Takeda et al. ${ }^{18}$ This induces the addition of $581.1 \mathrm{Da}\left({ }^{64} \mathrm{Zn}_{2} \mathrm{~L}^{3+}\right)$ as a triply charged tag. Typically, the mass spectra (data not shown) show all the peptides: $[\text { brady }+\mathrm{H}]^{+}$at $m / z=1060.5 \mathrm{Th}$, [angII $\left.+\mathrm{H}\right]^{+}$ at $m / z=1046.5 \mathrm{Th}$, [p_angII $+\mathrm{H}]^{+}$at $m / z=1126.5 \mathrm{Th}$, and $[\mathrm{K} 18+\mathrm{H}]^{+}$at $m / z=1418.4 \mathrm{Th}$. The tagged phosphopeptides were observed as a doubly charged species: [p_angII + tag $\mathrm{H}^{2+}$ at $m / z=852.8 \mathrm{Th}$, [p_angII + tag $\left.-2 \mathrm{H}\right]^{+}$at $m / z=1704.4$ Th, and $[\mathrm{K} 18+\mathrm{tag}-\mathrm{H}]^{2+}$ at $m / z=998.8 \mathrm{Th}$. (Due to the isotopic distribution being induced by $\mathrm{Zn}$ atoms, all the $\mathrm{m} / z$ values correspond to the monoisotopic masses.) An example of such mass spectra is shown in Supporting Information (SI), Figure S-1.

(46) Tang, K.; Page, J. S.; Smith, R. D. J. Am. Soc. Mass Spectrom. 2004, 15, 1416-1423.
These experiments show the selectivity of the tagging reaction toward the phosphopeptides, as the nonphosphorylated peptides were not affected. However, a peak at $m / z=1206.3$ Th appeared, corresponding to bradykinin bound to $\mathrm{PF}_{6}{ }^{-}$(counterion used in the chemical synthesis) showing a contamination of the sample. Other complexations were not observed. In addition, the tagging reaction was also carried out with a phosphothreonine-containing peptide (HTGpTGK) and highlighted the same behavior (data not shown).

Collision-induced dissociation (CID) experiments were performed on the tagged phosphopeptides (p_angII and K18 bound to the dinuclear zinc(II) complex) to confirm the specificity of such reactions (see SI Figure S-2). The common fragmentation pathway shows the loss of the tag together with the phosphate group. In each case, a typical peak $\left(\left[\operatorname{tag}+\mathrm{HPO}_{4}{ }^{2-}\right]^{+}\right)$at $m / z=$ 677.0 Th was observed. Two other fragments corroborated the specificity. The tagged p_angiotensin II fragmented near the zinc atoms, where one stays on the tag $(m / z=517.1 \mathrm{Th})$ and the other one on p_angII $(m / z=1188.3 \mathrm{Th})$. As for keratin K18, only the loss of water, the tag bound to $\mathrm{HPO}_{4}{ }^{2-}$ and the phosphopeptide without the phosphate moiety were observed. Unambiguously, the results highlight the specificity of the dinuclear zinc(II) complex for the phosphate group, as shown by Koike and coworkers. ${ }^{18,20}$ By this way, i.e., in CID fragmentation, the information on the phosphorylated site could be lost (cleavage of the $\mathrm{O}-\mathrm{C}$ bound). Nevertheless, the use of electron capture dissociation could avoid this problem in further experiments. ${ }^{47}$

Tagging Inside the Taylor Cone with a Dual-Channel Microsprayer. The tagging reactions were then carried out in situ by using a dual-channel microsprayer. As shown in Figure 1, the dual microsprayer consists of two different channels, one on each side of the polymer microchip. Each inlet serves for the infusion of two different liquids coming from the respective wells. At the tip of the microchip, the liquids are mixed within the Taylor cone. This region induces several swirls depending on the viscosity of the liquid. ${ }^{37}$ In this setup, well $\mathrm{B}$ was filled with the aqueous sample solution containing the peptides and well $\mathrm{A}$ with the tag in ACN. The platinum electrode immersed in well A induces the electrospray. The solution from the sample well was pumped by pressure-driven flow induced by the level of liquid present in the well. The liquid motion within this space gave a sufficient residence time for the complexation to take place, obviously depending on the kinetic constants. The tagging reactions were observed immediately. The mass spectrum in Figure $2 \mathrm{a}$ is related to this experiment with a concentration of tag equal to $10 \mu \mathrm{M}$. The reaction can occur within the Taylor cone, and the results are similar to those observed with the commercial source, even if unreacted tags can be observed at $m / z=320.1$ Th. In addition, the conversion rates appear rather higher than those obtained when the reaction was performed before the analysis. These results highlight that two different liquids such as water and acetonitrile can be efficiently mixed together in the Taylor cone, enabling the tagging reactions.

As performed previously with the commercial electrospray source, different concentrations of tag were used and the conversion rates were plotted against the concentration (see Figure 3). As shown in this graphic, three main points emerge: (i) the

(47) Sweet, S. M. M.; Cooper, H. J. Expert Rev. Proteomics 2007, 4, 149-159. 

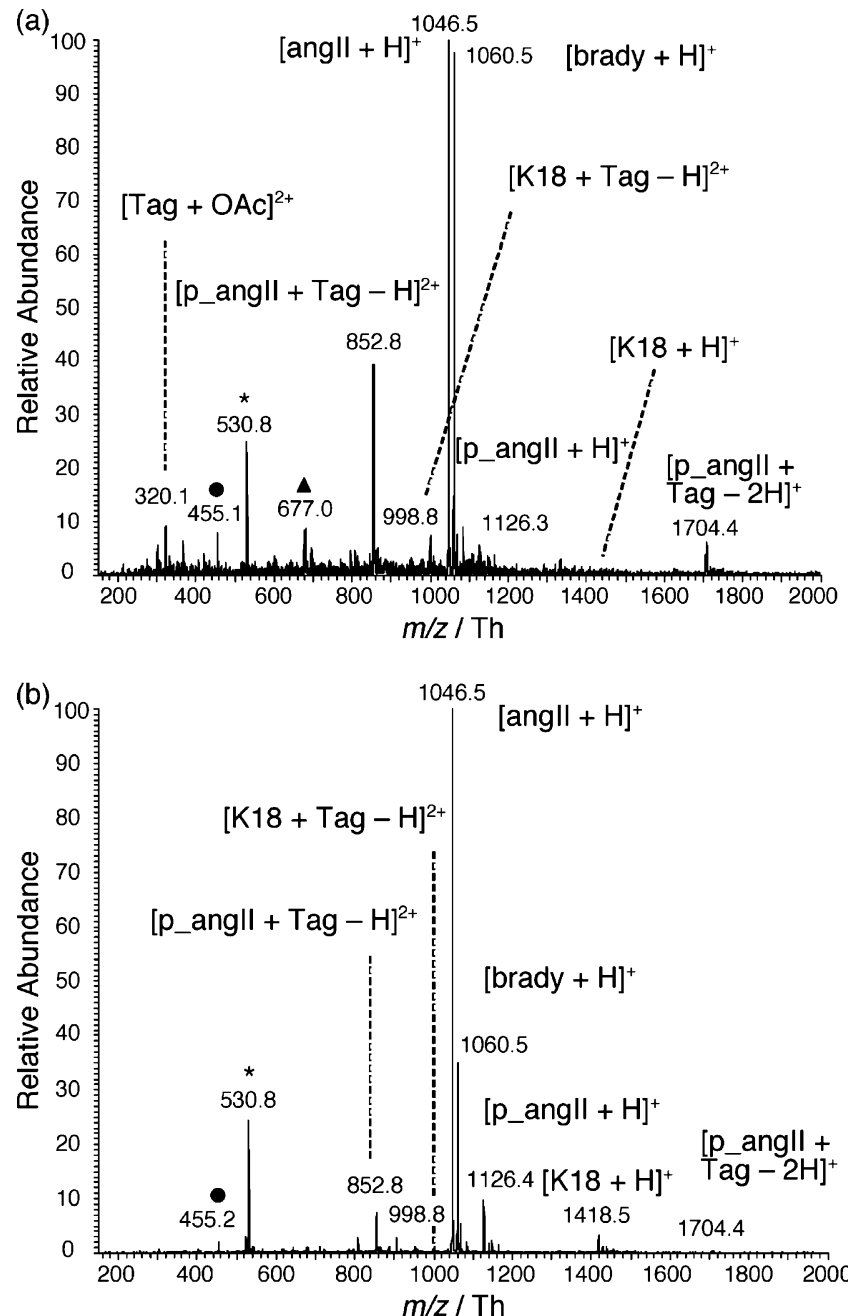

Figure 2. Tagging in dual-channel microchip. Mass spectra of a mixture of bradykinin, angiotensin II, P_angiotensin II, and keratin K18 (50 $\mu \mathrm{M}$ each) in water (well B) and in well A: (a) tag $(10 \mu \mathrm{M})$ in ACN, where a Pt electrode was immersed to enable the ESI process (absolute intensity $1.7 \times 10^{6}$ counts); or (b) $\mathrm{LH}(10 \mu \mathrm{M})$ in 2-propanol where a $\mathrm{Zn}$ electrode was immersed enabling the electrogeneration of $\mathrm{Zn}_{2} \mathrm{~L}^{3+}$ and the ESI process, $t=45$ min (absolute intensity $3.5 \times$ $10^{6}$ counts). ${ }^{*}[\text { brady }+2 \mathrm{H}]^{2+}, \mathbf{\Delta}\left[\mathrm{Tag}+\mathrm{HPO}_{4}{ }^{2-}\right]^{+}, \bullet[\mathrm{L}+2 \mathrm{H}]^{+}$. The mixing takes place within the Taylor cone.

conversion is higher than expected (according to the experimental setup and at equivalent concentration, the ratio tag/phosphate moiety is equal to $1 / 2$. The line in Figure 3 represents $\chi$ function of the tag concentration for a total reaction); (ii) the conversion is higher for p_angII compared to keratin K18 (especially with the commercial source); and (iii) the use of dual-channel microsprayers provides a higher conversion rate (black markers). Indeed, total conversion is almost reached with $20 \mu \mathrm{M}$ instead of $50 \mu \mathrm{M}$ when the reaction was performed prior to the analysis. The ionization efficiency is responsible for the first observation. The conversion rate calculated here represents the conversion observed in MS. As shown in Figure 2, the ionization efficiencies of such phosphocompounds are lower than other peptides due to the acidity induced by the PTM. The addition of a triply charged tag enhances the ionization and thus increases virtually $\chi$, as clearly shown in Figure 3 between the line and the markers. Remark ii can also be explained by the same effect; even unmodified K18 appears less abundant than p_angII. The tagging

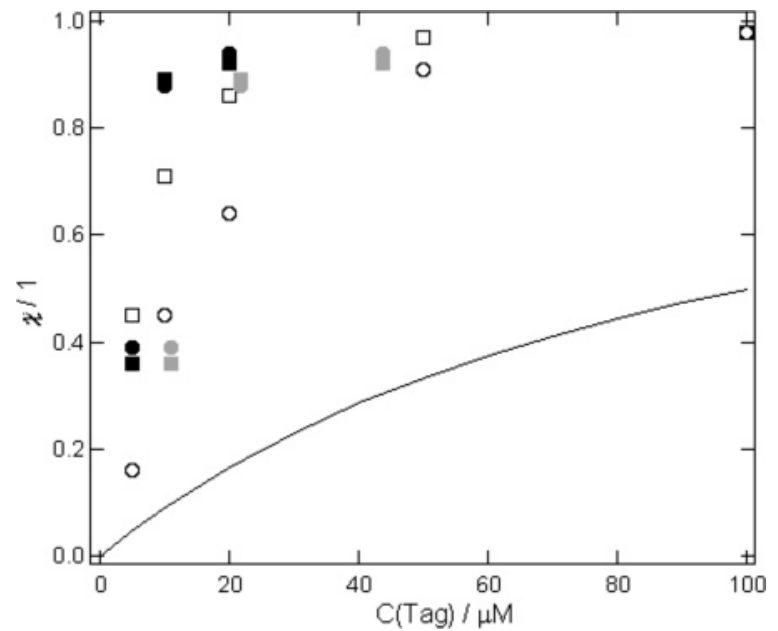

Figure 3. Conversion rate versus tag concentration. The line corresponds to the theoretical values of $\chi$ for a total reaction where one tag can react with two phosphate groups. Square and round markers stand for $\mathrm{p}$ _angll and $\mathrm{K} 18$, respectively. Empty and dark markers represent the tagging reactions prior to the analysis and within the Taylor cone, respectively. Gray markers correspond to the experimental values obtained with the dual-channel microsprayers where the tag concentrations were corrected according to the flow rate in each channel (see text for details).

reaction could also be different with these two different phosphopeptides. $\chi$ can decrease according to: the dimerization of keratin K18 via cysteine oxidation (data not shown) that could change the molecule reactivity; and the loss of [tag $\left.+\mathrm{HPO}_{4}{ }^{2-}\right]^{+}$related to the tagged K18 (not taken into account in the calculation).

Finally, the last point concerns mainly the design of the experiments. The reaction is achieved in a microtube in $50 / 50$ $\mathrm{ACN} / \mathrm{H}_{2} \mathrm{O}(\mathrm{v} / \mathrm{v})$ for the analysis with the commercial source and in the Taylor cone with the dual-channel microsprayer. To create a higher conversion (remark iii), a higher tag/peptide concentration ratio is required. It seems that the quantity of tag inside the Taylor cone is higher than expected. Indeed, the microsprayer has two distinct lines that feed the Taylor cone. If the flow rate is higher in the channel containing the tag, the quantity of tag inside the microreactor will be higher and then $\chi$ will increase. The flow rate of each line is governed by the volume of solution inside the wells. The electroosmotic flow can be neglected because of the material used (polyimide) and the experimental condition. ${ }^{48}$ The height of liquid $h$ present in the well controls the flow rate. ${ }^{34,49}$ The liquid in the reservoir induces a pressure drop $\Delta p$, which is related to the volumic flow rate $F_{\mathrm{V}}$ by Darcy's law for a channel of a length $l$ and a radius $r$.

$$
F_{\mathrm{V}}=\frac{\Delta p \pi r^{4}}{8 \eta l}=\frac{\rho g V r^{4}}{8 \eta l R^{2}}
$$

where $\rho$ is the liquid density, $g$ the gravity constant, $\eta$ the fluid viscosity, and $V$ the volume of solution in a well of a radius $R$. This equation has been validated experimentally by Rossier and co-workers. ${ }^{49}$

(48) Eijkel, J. C. T.; Bomer, J.; Tas, N. R.; Van Den Berg, A. Lab Chip 2004, 4 161-163.

(49) Morier, P.; Vollet, C.; Michel, P. E.; Reymond, F.; Rossier, J. S. Electrophoresis 2004, 25, 3761-3768. 


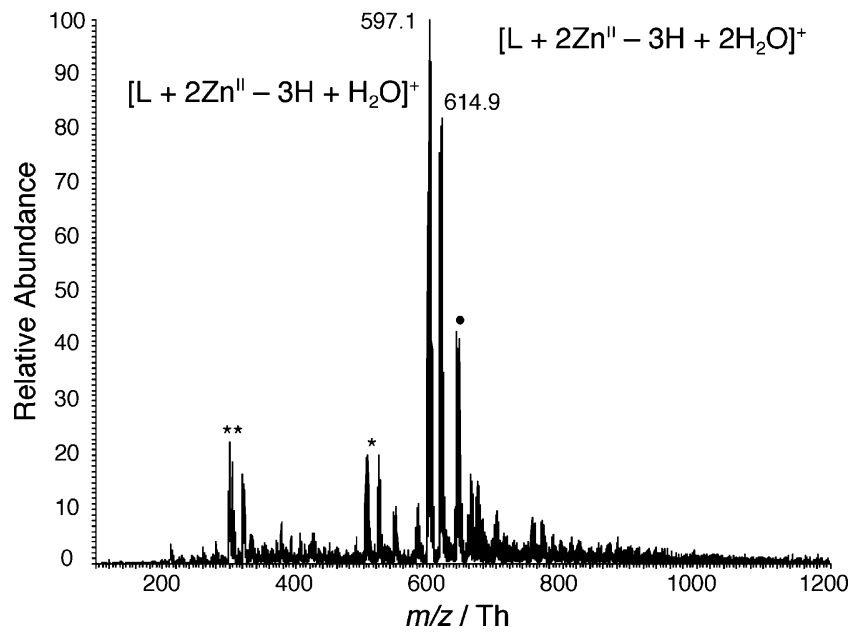

Figure 4. Mass spectrum of $\mathrm{L}(50 \mu \mathrm{M})$ in 50/50 2-propanol/water $(\mathrm{v} / \mathrm{v})$ performed with a $\mathrm{Zn}$ electrode, $t=29 \mathrm{~min}$. Single microchannel was used. * fragments; ${ }^{* *}$, doubly charged species; $\bullet$ tag probably coordinated with 2-propanol. Absolute intensity $9.7 \times 10^{6}$ counts.

For a radius $r$ estimated at $30 \mu \mathrm{m}$ and an initial volume of 100 $\mu \mathrm{L}$, the flow rate is equal to $144 \mathrm{~nL} / \mathrm{min}$ for ACN (containing the tag) and $66 \mathrm{~nL} / \mathrm{min}$ for $\mathrm{H}_{2} \mathrm{O}$ (containing the peptides). This difference in the flow rates will change the concentrations in the microreactor by a factor of 2.2. The gray markers in Figure 3 correspond to the experimental values obtained with the dualchannel microsprayer where the tag concentrations were corrected according to these flow rates. $\chi$ values become equivalent between the two setups, confirming the influence of the flow rate. In order to emphasize the influence of the physicochemical properties of the solution, the wells were also filled with a mixture of solvent, i.e., $\mathrm{ACN} / \mathrm{H}_{2} \mathrm{O}$ instead of pure water and pure acetonitrile. The results pointed out a lower value of $\chi$, as expected.

Tagging Inside the Taylor Cone with a Dual-Channel Microsprayer by Electrogeneration of $\mathbf{Z n}_{2} \mathbf{L}^{3+}$. Taking advantage of the inherent electrochemical nature of the electrospray ionization process, zinc(II) cations can be produced in situ by oxidation to form the tag. The gist of the present work is to couple the sacrificial zinc electrode with the dual-channel microchip in order to allow the tagging reaction without chemical synthesis. Figure 1 (on right) illustrates this principle.

To verify the concept, the ligand LH was electrosprayed with a zinc electrode in 2-propanol/water solution using only a single channel. In positive ionization mode, the zinc electrode is oxidized and $\mathrm{Zn}^{2+}$ is released in solution. The ligands then chelate these cations, the formation of the tag was fast, and different compounds coordinated with water were observed after a few minutes, such as $\left[\mathrm{L}+{ }^{64} \mathrm{Zn}^{\mathrm{II}}-\mathrm{H}\right]^{+}$at $m / z=517.1$ Th or $\left[\mathrm{L}+2^{64} \mathrm{Zn}^{\mathrm{II}}-3 \mathrm{H}+\right.$ $\left.2 \mathrm{H}_{2} \mathrm{O}\right]^{+}$at $m / z=614.9$ Th (see Figure 4). Both water and 2-propanol can bind at the fifth coordination site of a zinc(II) ion complexed by the ligand. According to their dissociation constant, a phosphate group can bind preferentially as a bridging ligand to the two zinc(II) cations. ${ }^{20}$ Hence, this complex was formed without any specific preparation and will be able to react with different phosphorylated compounds in ESI experiments. Only the configuration with two atoms of zinc $\left(\mathrm{Zn}_{2} \mathrm{~L}^{3+}\right)$ reacted in the following experiments.
The electrogeneration of the tag required making the reaction in a well with the ligand. Single channel, where LH and the phosphocompounds would be mixed, is not adapted. Indeed, the $\mathrm{Zn}^{2+}$ electrogenerated could bind either to L or to the phosphopeptides; even though it was observed that the tag was first formed, reacting with the phosphate moiety and then $\mathrm{Zn}^{2+}$ cations linked to the peptides. Separated cells are thus essential and the design of such dual-channel microsprayers becomes suitable.

The experiments were performed following the scheme in Figure 1. When the MS power supply was switched on, the $\mathrm{Zn}^{2+}$ generation began, reacting with the ligand to form the tag in well A or in the downstream microchannel. The complex formed by reaction of the phosphopeptides with the tag took place within the Taylor cone, and the products appeared in few minutes as a doubly charged species: [p_angII + tag $-\mathrm{H}]^{2+}$ at $m / z=852.8$ Th and $[\mathrm{K} 18+\operatorname{tag}-\mathrm{H}]^{2+}$ at $m / z=998.8 \mathrm{Th}$. Figure $2 \mathrm{~b}$ shows the mass spectrum obtained with a concentration of $\mathrm{L}$ equal to $10 \mu \mathrm{M}$. Different concentrations were used up to $50 \mu \mathrm{M}$. When using a high concentration, there were few contaminations of the spectra by the ligand and few derived products. The ionization efficiency of such compounds compared to the peptides explains this phenomenon. At $10 \mu \mathrm{M}$, the spectrum is clear without contamination. Moreover, in the absence of the counterion $\mathrm{PF}_{6}{ }^{-}$, the product observed at $m / z=1206.3$ Th according to the use of the synthesized tag was not observed here.

As a result, the relative abundance of the tagged p_angII and K18 increased with time (see conversion rate in Figure 5a). Adducts were present in a few minutes (even a few seconds for the tagged $\mathrm{p} \_$angII) and reached a conversion rate of $\sim 0.4$ after $45 \mathrm{~min}$ of experiment. The concentration of L being constant, this increase is due to $\mathrm{Zn}^{2+}$ production. Indeed, in this setup, there is an accumulation of $\mathrm{Zn}^{2+}$ and tag against time. Kebarle and coworkers have shown the relationship between the $\mathrm{Zn}^{2+}$ concentration (following the oxidation of the electrode) and the spray current $I .^{40}$ In our setup, i.e., using a sacrificial electrode immersed in a solution inside a well, there is an accumulation of cations, as observed with a copper electrode. ${ }^{43}$ According to the Faraday law, the quantity $n$ of $\mathrm{Zn}^{2+}$ is defined as

$$
n=I t / 2 F
$$

where $F$ is the Faraday constant and $t$ the time. If we consider the mass balance on the well, the variation of $n$ can be written

$$
\frac{\mathrm{d} n}{\mathrm{~d} t}=\frac{I}{2 F}-\frac{n F_{\mathrm{V}}}{V}
$$

where the first term on the right-hand side stands for the source, i.e., oxidation of the zinc electrode inside the reactor, and the second term stands for the output, the evaporation not being considered in the mass balance equation. According to eq 2 , the ratio $F_{\mathrm{V}} / V$ is independent of $h$ and thus of $t$. By integration, eq 4 becomes

$$
n=\frac{I}{2 F} \frac{V}{F_{\mathrm{V}}}\left(1-\mathrm{e}^{-F_{\mathrm{V}} t / V}\right)
$$



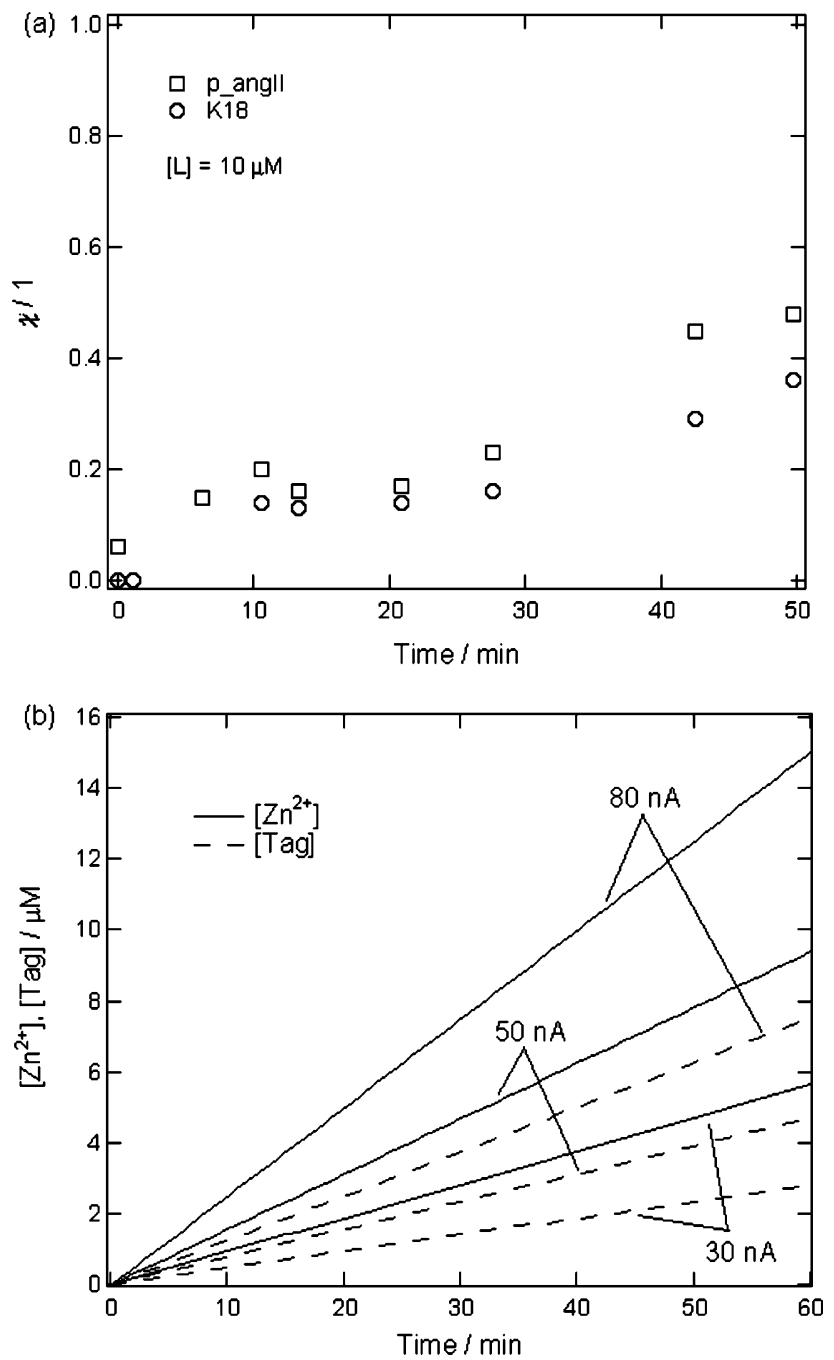

Figure 5. (a) Conversion rate versus time. $\chi$ increases thanks to the zinc oxidation and accumulation inside the well. (b) Theoretical evolution of $\mathrm{Zn}^{2+}$ and tag concentrations according to the spray current. The reaction between $2 \mathrm{Zn}^{2+}$ and $\mathrm{L}$ is considered as total. The calculation was made by taken into consideration a solution of 2-propanol, $V_{0}=100 \mu \mathrm{L}, r=30 \mu \mathrm{m}, R=3 \mathrm{~mm}$, and $I=1 \mathrm{~cm}$.

$$
V=V_{0}-F_{\mathrm{V}} t
$$

and where $V_{0}$ is the initial volume equal to $100 \mu \mathrm{L}$. At a time $t$, the volume is defined by eq 6 and will continuously decrease, as well the flow rate. Taken into consideration eq 2 , we can derive the volume at a time $t$ as follows:

$$
V=V_{0}\left(1+\frac{\rho g r^{4} t}{8 \eta l R^{2}}\right)^{-1}
$$

Numerical values of $V$ are obtained from eq 7 yielding $F_{\mathrm{V}}$, which can be used to calculate the $\mathrm{Zn}^{2+}$ concentration inside the well thanks to eq 5 .

Figure $5 \mathrm{~b}$ represents the increase of $\left[\mathrm{Zn}^{2+}\right]$ (solid line) and [Tag] (dash line) for the oxidation of a zinc electrode immersed in a 2-propanol solution. There is an accumulation of zinc(II) cations and tag with time inside the well. This variation is related to the solvent used inducing more or less a high flow rate. This calculation explained the evolution of the conversion rate versus the time observed in the mass spectrum.
In the presence of an excess of ligand (e.g., $10 \mu \mathrm{M}$ ), the tag concentration is in the micromolar range. This production is related to the spray current. The higher the current, the higher the $\mathrm{Zn}^{2+}$ concentration. In our setup, $I$ is defined (among other things) by the distance between the chip and the entrance of the MS, but a compromise needs to be obtained between the current and the spectra quality. In spite of this relative low concentration, the phosphopeptide tagging occurs easily in a few minutes. By convenience, a rather high concentration of peptides was used, but in the case of lower concentration, an efficient tagging can be reached in a few seconds.

\section{CONCLUSIONS}

All in all, this study highlights the advantage of such dualchannel electrospray sources. This device made of polyimide allows performing a tagging reaction within the Taylor cone and also the infusion of different solvents (water, acetonitrile, or 2-propanol).

Koike and co-workers ${ }^{18}$ have shown the specificity of this dinuclear zinc(II) complex in MALDI-MS. Here, we demonstrated that this tag could be used in ESI-MS and in addition enhances the ionization efficiency of phosphorylated peptides. The ex situ reaction, i.e., performing the tagging in a microtube prior to the analysis, allows a total conversion of the phospho compounds into the tagged species by using the adequate concentration, even though sample contaminations were observed by the counterion used during synthesis and the tag itself. The in situ tagging thanks to the use of a dual-channel microsprayer offers the same results by making the reaction only within the Taylor cone. The use of a zinc sacrificial electrode as an anode helps both the formation of the tag during the experiments thanks to zinc oxidation and the application of the spray current. The electrogenerated dinuclear zinc(II) complexes react with the phosphopeptides without any preparation of the complex before the analysis. The ease-of-use of such sacrificial electrodes has been already proved, avoiding the influence of counteranions. ${ }^{43,44}$ The drawback of such electrogeneration remains the relatively low tag production. This could be solved by using lower sample concentration or performing the electrogeneration in an electrochemical cell prior to the microchip inlet. 50,51

According to the configuration of this electrospray source, different coupling can be performed, for instance with on-line separation. Indeed, the dinuclear zinc(II) complex enables a direct tagging of phosphorylated peptides. Further studies will be performed with infusion lines in order to control/impose different flow rates. For a more fundamental view, the size of the microchannel will be studied. This parameter could have an influence on the size of the Taylor cone, the spray mode, and thus the mass spectra obtained. Moreover, we have shown that this device can serve to probe and better understand the reactivity inside the Taylor cone. Finally, the reactivity of this tag can be tested in different conditions, for kinetic studies or tagging of multiple/

(50) Xu, X. M.; Lu, W. Z.; Cole, R. B. Anal. Chem. 1996, 68, 4244-4253.

(51) Van Berkel, G. J.; Asano, K. G.; Granger, M. C. Anal. Chem. 2004, 76, 1493-1499. 
consecutive PTMs in peptides or proteins, for instance, but also with different phosphocompounds such as RNA.52,53

\section{ACKNOWLEDGMENT}

The Fonds National Suisse pour la Recherche Scientifique is thanked for financial support through the project "Analytical tools for fast phosphoproteome analysis” (Grant 200020-113413/1).

(52) Feng, G. Q.; Natale, D.; Prabaharan, R.; Mareque-Rivas, J. C.; Williams, N. H. Angew. Chem., Int. Ed. 2006, 45, 7056-7059.

(53) Feng, G. Q.; Mareque-Rivas, J. C.; Williams, N. H. Chem. Commun. 2006 , 1845-1847.

\section{SUPPORTING INFORMATION AVAILABLE}

Mass spectrum of the tagging reaction performed ex situ and analyzed with the commercial ESI source; [tag] $=10 \mu \mathrm{M}$. MS/ MS of the tagged p_angII and K18. This material is available free of charge via the Internet at http://pubs.acs.org.

Received for review December 11, 2007. Accepted January 15, 2008.

AC7025139 